\title{
Epidemiology of varicella in Slovenia over a 20-year period (1979-98)
}

\author{
M. SOČAN*, A. KRAIGHER AND L. PAHOR \\ Centre of Communicable Diseases, Institute of Public Health of the Republic of Slovenia, Trubarjeva 2, \\ 1000 Ljubljana
}

(Accepted 26 October 2000)

\section{SUMMARY}

Varicella is one of the most common childhood diseases. The course of the disease is usually mild and uncomplicated. In Slovenia, varicella is a notifiable communicable disease which must be reported. Data collected from 1979-98 were analysed. Over the 20-year period the number of varicella cases reported ranged from a low of 11086 (in 1994) to a maximum of 21141 (in 1987). During the last 10 years, the highest incidence of varicella was reported in children aged from 12 months to 2 years. In adults over 20, incidence has slightly but steadily increased over the 20 year period. Overall, the number of males with varicella exceeded that of females. The proportion of females was higher only in the 20-30-year age group, probably as a consequence of more frequent and closer contact with infected children by mothers. The highest number of reported cases was during winter and early spring.

\section{INTRODUCTION}

Varicella-zoster virus (VZV) causes varicella (chickenpox) and zoster (shingles). The virus is transmitted by infectious droplets suspended in air or by direct contact with the skin lesions of persons suffering from varicella or herpes zoster [1]. VZV can survive in the outside environment only for a short period of time and is mainly transmitted directly from a patient to a susceptible person [2]. VZV infection is usually symptomatic and it rarely occurs without the characteristic rash. The virus is very infectious; over $90 \%$ of susceptible individuals are infected after having been exposed to the virus $[1,3]$. Persons with varicella are infectious from a few days before the appearance of rash to until the last vesicle is dry [4].

Varicella infection occurs throughout the year, but its incidence is the highest in spring. The majority of children living in temperate climates acquire chickenpox by the age of 14 [5]. Only one fifth of children remain susceptible to the infection after the age of 8

* Author for correspondence.
[6]. Some recent studies have found an increase in the number of susceptible adults [7, 8]. The epidemiology of chickenpox in tropical countries is different, since fewer persons have chickenpox in childhood [9].

In Slovenia, the recommended measure for avoiding infection is to isolate the children who have varicella (from schools or nurseries) until the last vesicle has dried up. However, this measure reduces the incidence of the disease only slightly, since VZV is already present in respiratory secretions during the incubation period. In Slovenia, chickenpox has been a statutory notifiable disease for 23 years. This paper presents the epidemiological characteristics of reported varicella cases in Slovenia over a period of the last 20 years.

\section{METHODS}

Varicella became a statutory notifiable communicable disease in Slovenia in 1977. The registration form requires the following data: full name, age, date of onset of the disease. Since 1990, data have been collected on whether the child attended a day-care facility and whether he/she was hospitalized due to 


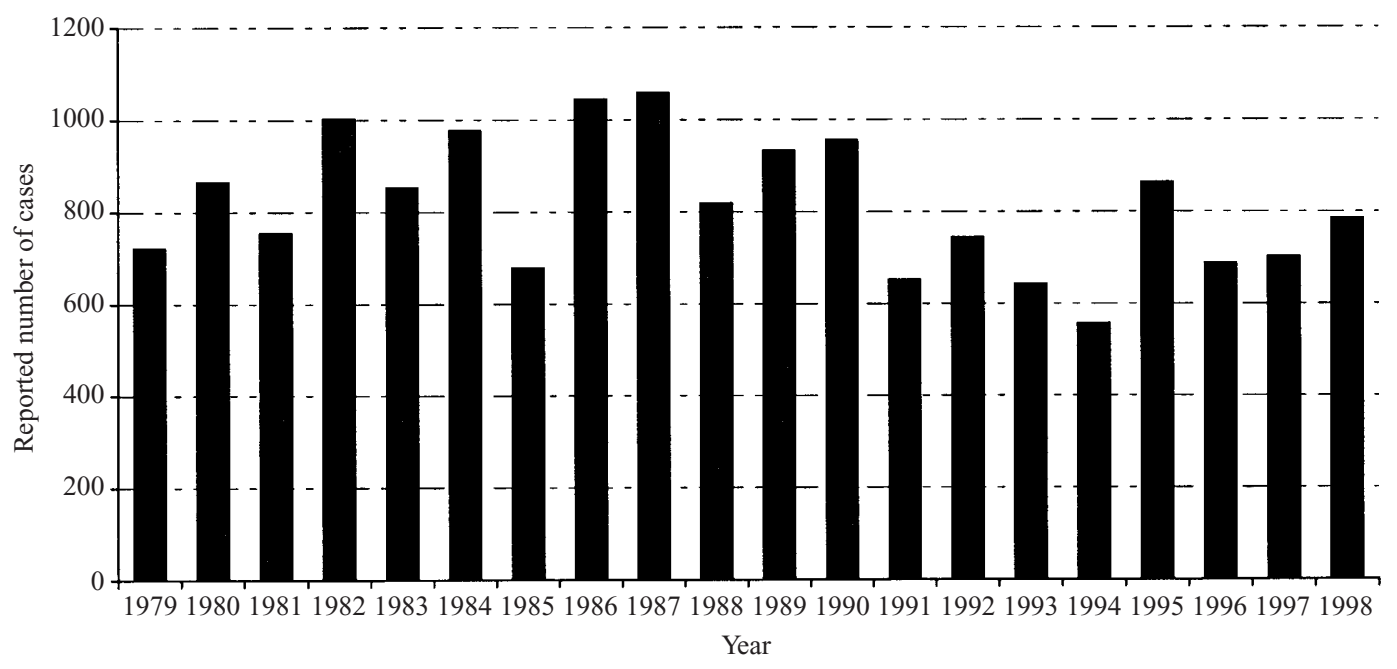

Fig. 1. Incidence of chickenpox from 1979 to 1998 in Slovenia.

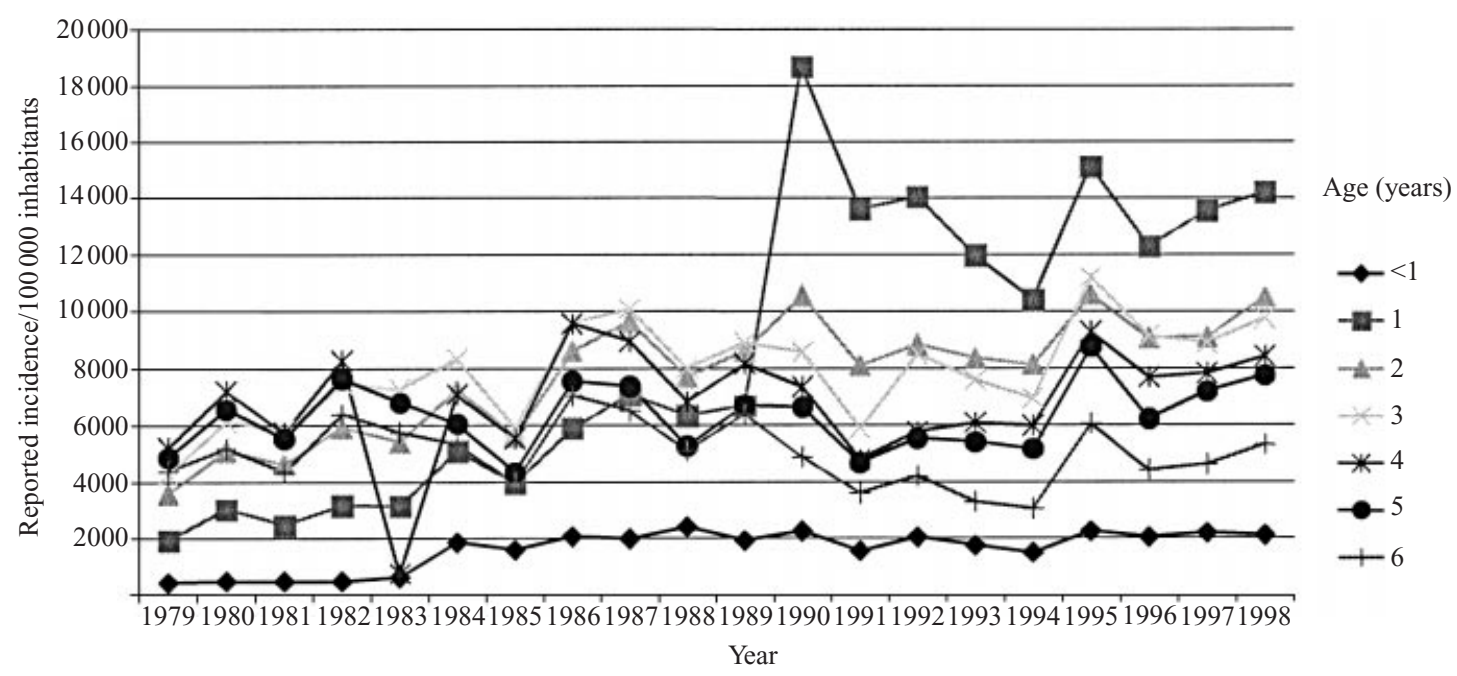

Fig. 2. Incidence of reported varicella cases in children less than six years of age.

varicella. Forms are collected at nine regional health care institutes and sent to the Institute of Public Health of the Republic of Slovenia. The data are published every year in its Annual Report on Communicable Diseases [10-13], while the demographic data are available in the Statistical Yearbook of the Republic of Slovenia [14-17]. The details of reported cases during 1979-98 were analysed.

\section{RESULTS}

A total of 321227 cases of varicella were reported over the 20 -year period. The annual reported incidence rate of varicella cases ranged from 11086 (in 1994) to a maximum of 21141 (in 1987). The average reported incidence for the 20-year period was $815 \cdot 2 / 100000$ (minimum 557.2 and maximum 1058 per 100000 ) inhabitants (Fig. 1). In this period, the population of
Slovenia increased from 1882295 to 1980000 , while the annual number of newborn babies decreased from 30604 in 1979 to 18165 in 1998.

As expected, the absolute number of varicella cases, as well as the reported incidence of varicella varied considerably between different age groups. The greatest number of varicella cases was reported in children up to 6 years of age (pre-schoolchildren), who accounted for $52-78 \%$ of all reported cases. In certain age groups, the percentage of varicella cases changed during the observed period. The percentage of children with varicella up to 1 year of age doubled, from $0.91 \%$ to $2.33 \%$. The greatest changes were observed in the age group of 1-2 years. In 1979, only $4.25 \%$ of reported varicella cases belonged to this age group, while in 1998 this had increased to $17 \cdot 13 \%$ (Fig. 2). In other age groups of preschoolchildren, there were no significant changes. 


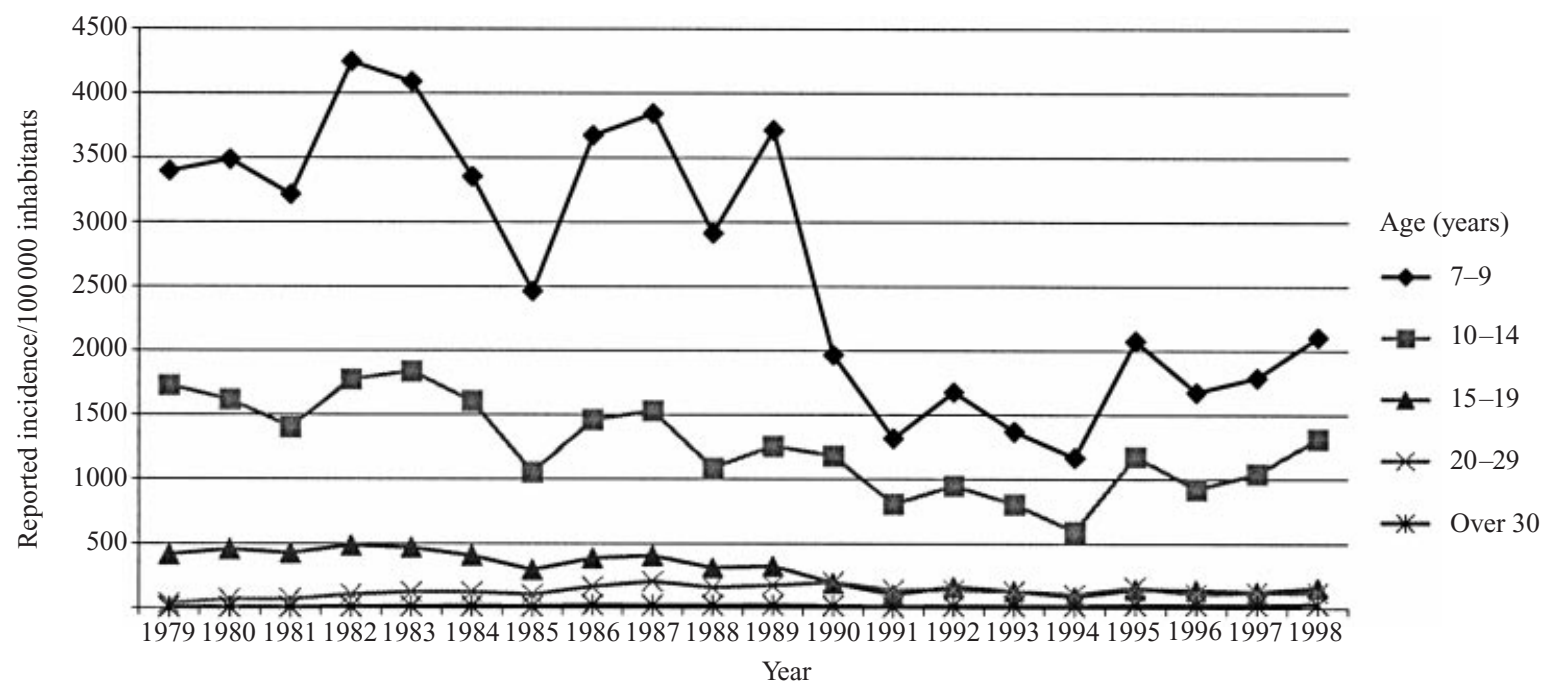

Fig. 3. Incidence of reported varicella cases in children older than six years of age and adults.

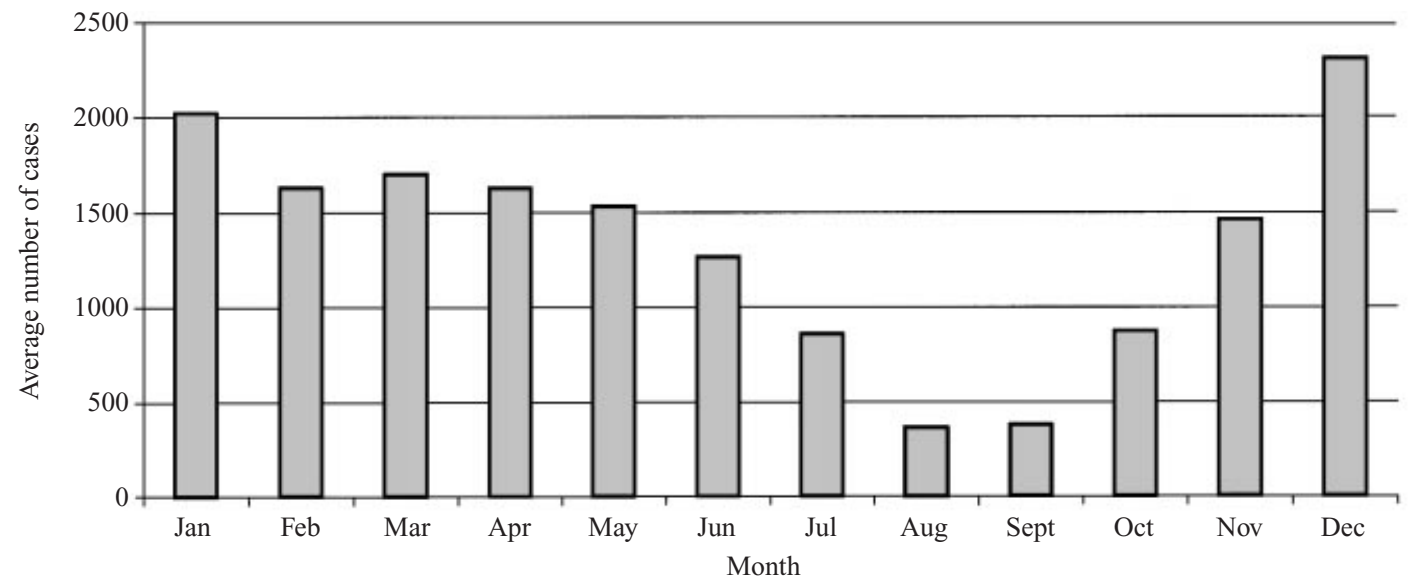

Fig. 4. Monthly distribution of the total number of reported varicella cases from year 1979 to year 1998.

Table 1. Number of hospitalized varicella cases from year 1979-98

\begin{tabular}{llcll}
\hline \hline Year & $\begin{array}{l}\text { Total reported } \\
\text { cases }\end{array}$ & $\begin{array}{l}\text { Total reported } \\
\text { hospitalized } \\
\text { cases }\end{array}$ & $\begin{array}{l}\text { Reported cases } \\
>15 \text { years }\end{array}$ & $\begin{array}{l}\text { Reported } \\
\text { hospitalized } \\
\text { cases }>15 \text { years }\end{array}$ \\
\hline 1990 & 19117 & 92 & 1092 & 5 \\
1991 & 13044 & 101 & 714 & 19 \\
1992 & 14845 & 106 & 837 & 17 \\
1993 & 12798 & 92 & 794 & 24 \\
1994 & 11086 & 44 & 646 & 4 \\
1995 & 17123 & 87 & 988 & 15 \\
1996 & 13700 & 69 & 815 & 13 \\
1997 & 13916 & 84 & 831 & 13 \\
1998 & 15538 & 70 & 937 & 13 \\
\hline \hline
\end{tabular}

The number of reported cases in primary schoolchildren (aged between 7 and 14 years) as well as in secondary school children (aged between 15 and 19 years) decreased steadily over the observed period (Fig. 3). The percentage of varicella cases in persons older than 20 was low. However, in this group two thirds of varicella cases were females and one third males. Overall, $50 \cdot 2 \%$ of cases were male and $49 \cdot 8 \%$ female. No significant differences were noticed between individual years. 
Each year, varicella cases peaked in the months of December and January, though not significantly more than during the period from February to April, while the lowest reported incidence rates were found in July and August (Fig. 4). Few patients were hospitalized due to varicella. Table 1 shows the number of hospitalized varicella cases by age. Even though persons above 15 years of age represent only $5.8 \%$ of all reported cases, $16.5 \%$ of all hospitalizations in the period from 1990-8 were from this age group.

\section{DISCUSSION}

The paper presents epidemiological data on varicella for the period from 1979-98. The incidence of reported varicella cases in Slovenia is on average 815.2/100000 (minimum 557.2 and maximum 1058 per 100000 inhabitants). It is smaller than that reported by the French Sentinelle system for control over certain communicable diseases [18] and greater than that reported in a study of varicella epidemiology in England and Wales for the period 1967-85 [19]. According to data from this 5-year French study, the incidence of varicella ranged from 1.0-1.35 per 100 inhabitants, while in the British study the established incidence was much lower, 243-878 varicella cases per 100000 inhabitants.

In the period 1979-89, the greatest number of reported varicella cases was in the 3-5 years age group, while after 1990 it was in the $1-2$ years age group. There was no significant variation in the annual incidence. Fairley noticed an increase in consultations for varicella in children younger than 5, which was probably the result of earlier inclusion of children into various day-care centres [20]. According to data from a French study, one half of varicella cases were children between the ages of 1 and 4, while those over 15 years of age accounted for a very small percentage [18]. According to data published in the Statistical Yearbook of Slovenia, $53 \cdot 1 \%$ of all children between the ages of 2 and 6 attended a day-care facility in 1979 , while 20 years later there were as many as $73 \%$. Only $10 \%$ of children between the ages of 1 and 3 attended a day-care facility in 1979, while 8 years later there were as many as $22 \%[14,16]$. Early exposure to VZV in day-care facilities is probably the cause of a greater reported incidence of this disease among toddlers.

Very young children (less than 1 year of age) do not attend day-care facilities in Slovenia because maternity leave lasts for 12 months and children less than
10 months of age are not accepted in kindergarten, so they are cared for at home. Nevertheless, the percentage of children with varicella, less than 1 year of age, doubled.

The number of reported varicella cases in the age group over 30 years was very small, but the incidence undoubtedly increased over the observed period. In 1979 , only 6.0 reported male varicella cases per 100000 inhabitants were older than 30 years, while in 1998 this number increased to 33.4 per 100000. However, the number of reported varicella cases in adults was still considerably lower than the number of consultations for varicella in persons older than 15 years of age in England and Wales, where these cases accounted for almost one fourth of all cases [20]. This difference may reflect different social environments in particular, the use of day-care facilities for toddlers. If a mother of a sick child in Slovenia is absent from work to look after her child, she will receive a compensation of salary only if she obtains a certificate from the paediatrician that the child was sick. For this reason, paediatricians in Slovenia probably see many more children with uncomplicated varicella than in countries in which fewer women are employed.

Over the 20-year period, there were no significant differences between morbidity of boys and girls, even though average reported incidence was slightly higher in males than in females. Similar findings have been reported in other studies [19]. However, between the ages of 20 and 29 years, approximately one third more females than males had varicella, which probably resulted from closer contact of mothers with small children with varicella.

The greatest number of reported cases over the 20year period occurred in the months of December and January. In the United States, the greatest number of varicella cases occurred between March and May [3], and in France, in June and July [18]. No explanation was found as to why the greatest number of cases in these two countries occurred during a different part of the year than in our country. The greatest morbidity during the coldest months of the year, when the days are shortest, seems to us understandable. During this time, children spend more time closer together, in enclosed spaces, which makes the transmission of VZV easier.

The epidemiology of varicella in Slovenia is based merely on reported cases, therefore the recorded incidence is undoubtedly lower than it would have been, had there been more active supervision. The reporting programme did not change over this time 
period. The following observed changes can be noticed: the increased incidence of varicella in very small children and in young adults. The epidemiological changes concerning varicella will need to be taken into account when planning possible vaccination programmes against varicella.

\section{REFERENCES}

1. Weller TH. Varicella and herpes zoster. Changing concepts of the natural history, control, and importance of not-so-benign virus. N Engl J Med 1983; 309: 1362-8.

2. Miller E, Marshall R, Vurdien J. Epidemiology, outcome and control of varicella-zoster infection. Rev Med Microbiol 1993; 4: 222-30.

3. Straus SE, Ostrove JM, Inchaupse G, et al. Varicellazoster infections. Biology, natural history, treatment, and prevention. Ann Intern Med 1988; 108: 221-37.

4. Arvin MA. Varicella-zoster virus. Clin Microbiol Rev 1996; 9: 361-81.

5. Choo PW, Donhue JG, Manson JE, Platt R. The epidemiology of varicella and its complications. J Infect Dis 1994; 172: 706-12.

6. Finger R, Hughes JP, Meade BJ, Pelletier AR, Palmer CT. Age-specific incidence of chickenpox. Public Health Rep 1994; 109: 750-5.

7. Gray GC, Palinkas LA, Kelley PW. Increasing incidence of varicella hospitalisations in United States army and navy personnel: are today's teenagers more susceptible? Should the recruits be vaccinated? Pediatrics $1990 ; 86$ : 867-73.
8. Miller E, Vurdien J, Farrington P. Shift in age in chickenpox. Lancet 1993; 341: 308-9.

9. Garnett GP, Cox MJ, Bundy AP, Didier JM, Catharine JS. The age of infection with varicella-zoster virus in $\mathrm{St}$ Lucia, West Indies. Epidemiol Infect 1993; 110: 361-72.

10. Varicella. Annual Report on Communicable Diseases. Zdrav Var 1984; 23 (suppl 4): 5-8.

11. Varicella. Annual Report on Communicable Diseases. Zdrav Var 1989; 28 (suppl 4): 3-5.

12. Varicella. Annual Report on Communicable Diseases. Zdrav Var 1994; 33 (suppl 4): 5-7.

13. Varicella. Annual Report on Communicable Diseases. Zdrav Var 2000; 38 (suppl 4): 9-10.

14. Population. In: Statistical yearbook of the Socialist Republic of Slovenia. Publication of Statistical Office of the Republic of Slovenia 1984; XXIII: 68-79.

15. Population. In: Statistical yearbook of the Socialist Republic of Slovenia. Publication of Statistical Office of the Republic of Slovenia 1989; XXVIII: 72-80.

16. Population. In: Statistical yearbook of the Republic of Slovenia. Publication of Statistical Office of the Republic of Slovenia 1994; XXXIII: 79-89.

17. Population. In: Statistical yearbook of the Republic of Slovenia. Publication of Statistical Office of the Republic of Slovenia 1999; XXXVIII: 64-76.

18. Deguen S, Chau NP, Flahault A. Epidemiology of chickenpox in France. J Epidemiol Commun Health 1998; 52 (suppl 1): 46-9S.

19. Joseph CA, Noah ND. Epidemiology of chickenpox in England and Wales, 1967-85. BMJ 1988; 296: 673-6.

20. Fairley CK, Miller E. Varicella-zoster virus epidemiology - a changing scene? J Infect Dis 1996; 174 (suppl 3): $\mathrm{S} 314-9$. 